\title{
BMJ Open Workplace health promotion for employees working in offshore wind parks in the German exclusive economic zone: a mixed-methods study
}

\author{
Janika Mette, Marcial Velasco Garrido, Alexandra Marita Preisser, Volker Harth, \\ Stefanie Mache
}

To cite: Mette J, Velasco Garrido M, Preisser AM, et al. Workplace health promotion for employees working in offshore wind parks in the German exclusive economic zone: a mixedmethods study. BMJ Open 2018;8:e020493. doi:10.1136/ bmjopen-2017-020493

- Prepublication history and additional material for this paper are available online. To view these files, please visit the journal online (http://dx.doi org/10.1136/bmjopen-2017020493).

Received 7 November 2017 Revised 28 June 2018 Accepted 9 July 2018
Check for updates

(c) Author(s) (or their employer(s)) 2018. Re-use permitted under CC BY-NC. No commercial re-use. See rights and permissions. Published by BMJ.

Institute for Occupational and Maritime Medicine, University Medical Center HamburgEppendorf, Hamburg, Germany

Correspondence to Janika Mette; j.mette@uke.de

\section{ABSTRACT}

Objectives To investigate the awareness and use of health promotion offers among offshore wind workers and to study associations with demographic and workplace characteristics. To examine employees' reasons for (non-)participation and their wishes for health promotion activities offshore.

Design Mixed-methods study presenting the results from semistructured telephone interviews and a web-based cross-sectional survey.

Setting Offshore wind parks in the German exclusive economic zone in the North and Baltic Seas.

Participants 21 offshore workers in the qualitative study (19 male/2 female; all German). 303 offshore workers in the quantitative study (287 male/13 female; 275 German/24 other nationalities).

Outcome measures Awareness and use of workplace health promotion offers and associations with demographic and workplace characteristics (age, work schedule and wind park phase); reasons for (non-) participation; needs and wishes for health promotion offers.

Results Few workers indicated being aware of health promotion programmes at their workplace. Single offers were reported, with fitness facilities being the most common offer employees recognised and had used ( $n=168,55.6 \%$ ). Employees with a regular work schedule were more likely to have used fitness facilities offshore (adjusted $O R(A O R)=3.22$, $95 \% \mathrm{Cl} 1.53$ to 6.80 ). Workers in the construction phase were more likely to have used massages ( $\mathrm{AOR}=8.19,95 \% \mathrm{Cl} 2.82$ to 23.77). Younger workers were less likely to belong to the group of those who were aware of fitness facilities but had not used them ( $A 0 \mathrm{R}=0.43,95 \% \mathrm{Cl} 0.19$ to 0.98 ). Employees expressed various needs and wishes for behavioural and environmental preventive measures offshore.

Conclusions The results demonstrate a perceived need among the workers for the development of health promotion programmes offshore. Since the awareness and use of offers may partly depend on personal and organisational characteristics, this should be taken into account in the planning of health promotion activities.

\section{INTRODUCTION}

In recent years, the working world has undergone fundamental changes, for example, in
Strengths and limitations of this study

- This is the first study to provide detailed insight into the awareness and use of workplace health promotion offers among workers in German offshore wind parks and to reveal offshore workers' needs regarding health promotion activities.

- A particular strength of the study lies in its sequential mixed-methods approach, providing both qualitative and quantitative data on the topic and expanding the current scientific evidence.

- A methodological limitation of the qualitative study consists of the use of telephone instead of face-to-face-interviews.

- Methodological concerns regarding the quantitative study are the exclusive reliance on self-reported information and the increased likelihood of self-selection among the survey respondents.

terms of globalisation, demographical and structural changes. ${ }^{12}$ Substantial increases in work-related psychosocial risk factors as well as in days of incapacity to work due to psychological diseases have been observed. ${ }^{13}$ As a consequence, the need to foster employees' health and sustain employability is becoming increasingly important. Today, the workplace is being used to a greater extent as a setting for prevention and health promotion. ${ }^{4-6}$

Promoting workers' health is particularly relevant in work areas in which employees encounter high physical and psychological job demands. One such demanding field is offshore work. Offshore employees (eg, in the wind and oil and gas industry) work in a uniquely inhospitable environment ${ }^{7}$ and are confronted with diverse hazards with regard to their health and safety. ${ }^{8-10}$ Research suggests that offshore workers typically face high quantitative demands (eg, time pressure), ${ }^{8} 1112$ experience intensive work patterns (shift work, commonly 12 work hours a day), ${ }^{781314}$ are exposed to harsh 
weather conditions (eg, heat and cold $)^{1516}$ and must deal with recurrent periods of absence from home (usually 2-week or 3-week absences). ${ }^{10} 1718$ Such job demands are assumed to increase occupational strain and health complaints among the workers. ${ }^{9}$ Indeed, studies in the offshore oil and gas industry showed that perceived job demands of oil and gas workers were linked to physical and mental health impairment. ${ }^{10-12} 19{ }^{20}$ Evidence based on studies among offshore wind workers is still limited. However, recently published studies suggest similar associations between offshore wind workers' job demands, physical and mental strain (eg, increased stress, fatigue and sleep problems)..$^{91}$

In view of the multiple demands and health risks workers in offshore industries face, health promotion for these working groups seems mandatory. This study specifically focuses on workplace health promotion in the expanding German offshore wind industry. Since the commissioning of the first wind park in 2010, the industry has increased rapidly. In 2016, approximately 27200 workers were employed in the branch, from which 7600 persons were assumed to directly perform operation and maintenance tasks in offshore wind parks. ${ }^{22}$

Due to the industry's young age, little is known about health promotion within this specific branch. The only offers currently documented for German offshore workers are the provision of gyms offshore as well as discounts on gym memberships and organised sport events onshore. ${ }^{23}$ It otherwise remains unclear whether any other health promotion programmes are available and attended by the workforce and what the workers' needs and wishes on the topic are. Such information is, however, vital to the design of interventions that can meet this group of workers' specific needs and promote their health. This is essential from an employee's perspective and crucial for offshore employers and the industry as a whole to secure productivity and economic growth.

In contrast, workplace health promotion initiatives have been reported for workers in the offshore oil and gas industries (eg, Norway and UK) ${ }^{24-26}$ They included fitness programmes and facilities, individual and ergonomics counselling, smoking cessation and initiatives to foster offshore workers' hearing conservation, circadian adaptation, weight loss and healthy eating. ${ }^{24-28}$ Positive effects of the programmes on offshore workers' health, ${ }^{7}$ commitment, safety behaviours and the general safety climate $^{2629}$ have been reported. Such findings may be helpful when designing programmes for offshore wind workers, as they indicate areas for intervention and their suitability for the offshore setting. However, the results are not directly transferable to the offshore wind industry. Although work in offshore branches has certain features in common (eg, remote workplaces and long work shifts), there remain distinctive differences, for example, in terms of the industries' regulations and the extension of work areas. ${ }^{21}{ }^{30}$ Contrary to oil and gas workers, offshore wind workers must be transferred frequently to the offshore installations by ship or helicopter. They work on wind turbines at high altitudes and carry special safety equipment. ${ }^{21}$ These particularities could be linked to specific health hazards for the workforce, such as an increased risk of falls from height or accidents during the transfer.

\section{Theoretical and empirical framework}

A useful framework for studying health promotion in the offshore setting is provided by the Luxembourg Declaration on Workplace Health Promotion, defining workplace health promotion as 'the combined efforts of employees, employers and society to improve the health and well-being of people at work' ${ }^{31}$ Such efforts can be classified into behavioural and environmental preventive measures. While behavioural measures aim at changing behavioural patterns of individuals or groups without explicit contextual references, environmental measures refer to structural and political interventions to influence health-related ecological, social, cultural and technical material environments. ${ }^{32}$ Meta-analyses conclude that workplace health promotion can exert positive effects on employees' healthy eating and dietary behaviours, ${ }^{33} 34$ physical activity and fitness, ${ }^{3536}$ body weight ${ }^{3437}$ and mental well-being. ${ }^{38}$ In addition, positive effects in terms of decreased sickness absences, ${ }^{35} 3839$ reduced job stress ${ }^{35}$ and increased work ability ${ }^{38}$ were shown. The economic benefits of workplace health promotion are confirmed by a high return on investment. ${ }^{4041}$ In sum, evidence suggests that health promotion can impact positively on several health components that should ideally be addressed in an all-encompassing approach for offshore wind workers.

\section{Study aims}

The aim of our study was to investigate the awareness and use of workplace health promotion offers among workers in German offshore wind parks. We also intended to study the influence of demographic and workplace characteristics in this context, since knowledge thereof could be useful to level out differences in the workers' awareness and use of offers. Based on plausibility considerations, we considered employees' work schedule, age and the phase of the wind park they worked in to be of potential relevance. Offshore employees' work schedules differ considerably in terms of the time they spend offshore. Since irregular work schedules were found to be linked to reduced feasibility and sustainability of workplace health promotion, ${ }^{42}$ the work schedule could impact on offshore employees' awareness and use of offers. Moreover, employees' age could play a role, as evidence suggests a tendency for older workers to be less likely to participate in health promotion activities. ${ }^{5}$ The phase of the offshore wind park could also influence employees' levels of awareness and use: a recent study has indicated work in the construction phase to be associated with higher physical demands (eg, higher levels of climbing and carrying heavy loads), ${ }^{21}$ which could influence employees' participation rates. Moreover, we aimed to examine employees' reasons for (non-) participation in offers and their needs and wishes for health promotion activities offshore. 


\section{Research questions}

1. What are the levels of awareness and use of health promotion offers among employees in German offshore wind parks?

2. Is there an association between demographic as well as workplace characteristics (age, work schedule and wind park phase) and employees' awareness and use of offers?

3. What are employees' reasons for (non-) participation in health promotion offers?

4. What are employees' needs and wishes for workplace health promotion offers and general improvement of their health offshore?

\section{METHODS}

We conducted a sequential mixed-methods study, applying both a qualitative and quantitative research approach. ${ }^{43}$ Semistructured interviews were conducted to gain explorative insights into the topics. The explorative results were then used as a basis for the design of an online survey to collect quantitative data.

\section{Qualitative approach}

\section{Design, participants and recruitment}

We conducted 21 semistructured telephone interviews with workers in German offshore wind parks in July and August 2016. The interviews were carried out by the first author, a researcher (psychologist, MSc) with prior experiences in qualitative research. Eligibility criteria included a minimum age of 18 years, fluency in the German language, a regular work schedule and a minimum of 6 months of offshore experience. Purposive sampling was used to incorporate participants with varying demographic backgrounds (age, occupation and years of offshore experience). To promote the interview study, we sent information leaflets to small-sized, medium-sized and large-sized German offshore wind companies and company physicians via mail and email. In addition, we presented the study during health and safety trainings for offshore workers and encouraged the workers to share the information with their colleagues. All workers participated in the study voluntarily. Prior to the interviews, participants received the study information and signed a written informed consent. They were interviewed either during their offshore turns or during their free time onshore. The interviews were carried out until data saturation was reached, that is, no new themes emerged from the interviews. They were conducted in German and tape recorded. Interview length varied from $27 \mathrm{~min}$ to $60 \mathrm{~min}$. Field notes were made immediately after each interview.

\section{Interview guideline}

We developed a semistructured interview guideline including different topics (box 1). The relevant questions of the guideline are provided in online supplementary appendix A. Further topics (eg, concerning employees' working conditions) that were part of the guideline are presented elsewhere. ${ }^{89}$ An experienced offshore worker

Box 1 Interview topics

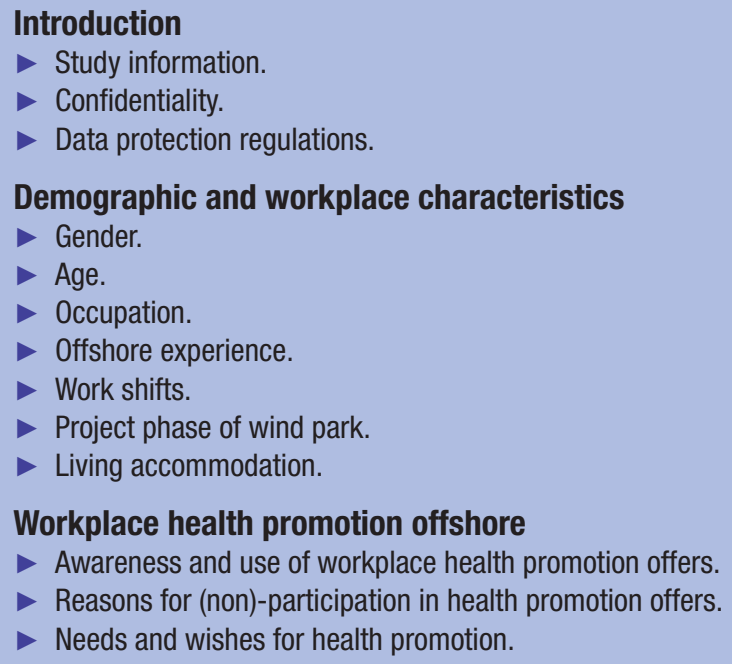

piloted the guideline, which was further revised based on the worker's recommendations.

\section{Analysis}

All audio recordings were transcribed, anonymised and double-checked against the recordings for accuracy. The transcripts were analysed by the first author by means of MAXQDA Analytics Pro software (V.12). ${ }^{44}$ A deductive-inductive approach following Mayring's qualitative content analysis was applied. ${ }^{45}$ A coding system was established and refined in an iterative process. Several categories and subcategories were obtained and summarised in a separate document in which the material was further compacted. The findings were profoundly discussed within the group of researchers. The researchers' personal involvement and preconceptions were also reflected. Citations were translated by an English native speaker for publication purposes.

\section{Quantitative approach}

Design, participants and procedures

A web-based cross-sectional survey in both German and English was conducted between September 2016 and January 2017. The sample consisted of employees working in offshore wind parks in the German exclusive economic zone. We carried out an internet search to identify offshore companies and service providers. We contacted 50 industry players (small, medium and large sized) via telephone or email to inform them about the study, sent leaflets in German and English to them and asked them to disseminate the information (eg, via email, intranet, newsletters and word-of-mouth promotion). As an incentive to participate, companies were given the opportunity to receive the anonymised study results. We also contacted 40 German occupational physicians that had participated in a workshop on occupational medicine in the German offshore wind industry. Moreover, we posted the study information on five online forums for offshore 
wind workers and presented the study at an offshore fair ('WindEnergy 2016') and at the 'Round-table Maritime Safety Partnership' meeting organised by the German Offshore Wind Energy Foundation. Participants of the interview study were also invited to take part in the survey. All participants could access the survey via electronic devices by entering a URL or using a QR code. Participation in the study was voluntary. Participants were informed about the study aims and data protection regulations and were required to sign a declaration of informed consent prior to data collection.

\section{Variables}

\section{Demographic and workplace variables}

The following demographic variables were assessed: gender, age, relationship status, nationality, occupation, offshore experience, wind park phase, work schedule, work shifts, living accommodation and type of cabin.

\section{Workplace health promotion}

Due to a lack of validated items assessing health promotion offshore, we designed questions based on items previously used in the 'Health at Work Questionnaire'? This questionnaire was developed to examine health behaviours and health promotion practices on offshore oil and gas installations in the UK. In our survey, the first question on health promotion concerned offshore workers' awareness and use of health promotion offers ('Are you aware of any of the following health promotion activities at your offshore workplace?'). A range of activities was predefined, and employees were asked to select whether they were (1) not aware of them, (2) aware of them but had not yet participated in them or (3) aware of them and had participated in them. A free-text field was provided for detailing further offers. A multiple answer question was used to inquire about employees' reasons for non-participation in activities ('If you have not yet participated in any health promotion activities offshore, what are the reasons?'). Employees could select several reasons (eg, not interested in activities and too tired after work), with a freetext field allowing them to indicate additional reasons. We also included a question regarding employees' needs for improving their health offshore ('In your opinion: what could be done to improve your personal health at your offshore workplace?') and provided them with a free-text field to explain their views. In addition, the survey consisted of further scales that are presented elsewhere $\left(\mathrm{eg},{ }^{21}\right)$.

\section{Statistical analysis}

The statistical analysis was performed with IBM SPSS Statistics (V.24). ${ }^{46}$ Data were checked for plausibility and verified for outliers. Blank answers were treated as missing values. Descriptive statistical analysis was performed to obtain frequencies for the variables. $\chi^{2}$ tests and multinomial logistic regression analysis were used to investigate associations between demographic as well as workplace characteristics (age, work schedule and phase of the wind park) and employees' awareness
Table 1 Participant characteristics $(n=21)$

\section{n}

\begin{tabular}{lc}
\hline Gender & 19 \\
\hline Male & 2 \\
\hline Female & \\
\hline Age (years) & 5 \\
\hline $20-30$ & 11 \\
$31-40$ & 5 \\
\hline 41 & \\
\hline Relationship status & 18 \\
\hline In a relationship & 3 \\
\hline Single & \\
\hline Occupation & 4 \\
\hline Management offshore/supervisor & 6 \\
\hline Technician/mechanic & 3 \\
\hline Medical staff & 5 \\
\hline Quality, maintenance & 3 \\
\hline Health and safety staff & \\
\hline Offshore experience (years) & 2 \\
\hline$<1$ & 9 \\
\hline $1-2$ & 5 \\
\hline $3-4$ & 5 \\
\hline$>4$ & 5 \\
\hline Phase of wind park & 16 \\
\hline In construction & \\
\hline In operation & \\
\hline & \\
\hline
\end{tabular}

and use of health promotion offers. These analyses were adjusted for employees' occupation and type of shift work. Logistic regression analysis was only applicable to two offers (fitness facilities and massages), as the others did not meet the conditions for applying the procedure (too low frequencies per cell). The statistical significance level was set at $\mathrm{p}<0.05$. Answers from the free-text fields were summarised in a separate document and classified into categories and subcategories for numerical values.

Patient and public involvement

Patients and public were not involved in the study.

\section{RESULTS}

\section{Qualitative approach}

\section{Participant characteristics}

In the interview sample, 19 employees were male (table 1 ). Eleven workers were aged between 31 years and 40 years. The majority of the workers were technicians $(n=6)$ or worked in quality and maintenance $(\mathrm{n}=5)$. Employees' average work experience in the offshore wind industry was 3.4 years (range: 7 months-8 years). Ten workers had at least 3 years of offshore experience. Sixteen employees worked in wind parks in the operation phase. The 
interviewees represented nine different companies in the German offshore wind branch.

\section{Interview themes}

\section{Awareness and use of health promotion activities offshore}

From the 21 workers we interviewed, only two workers indicated being aware of a health promotion programme at their workplace, and both were from the same company. These two workers reported satisfaction with the health promotion programme, considered it to be well accepted by their colleagues and expressed appreciation towards their company for having initiated the programme:

You have to acknowledge that this is something that is provided by the company, that's a really great thing. (Worker $\# 19, \geq 41$ years, $1-2$ years offshore experience)

The programme addressed multiple health-related aspects, such as nutrition, physical activity and stress management. The interviewees explained that all workers on the platform had initially received individual counselling as well as customised exercise and dietary plans. Moreover, group workouts were organised on the platform, and the workers were provided with a web-based application to monitor their training. The first successes of the programme were reported, for example, that some workers had begun following a healthier diet:

There really are a lot of people who have changed their eating habits. One of my colleagues used to have thick slices of toast with thick layers of cold cuts, two fried eggs, and a huge pool of ketchup for breakfast. He doesn't do that anymore. So it's clear that the program has already been successful. (Worker $\# 19, \geq 41$ years, $1-2$ years offshore experience)

All of the other interviewees reported not knowing about specific health promotion programmes at their workplaces. As an explanation, it was stated that health promotion was primarily a question of cost for the companies:

It's another cost factor [...] that just can't be accommodated. (Worker \#16, 31-40 years, >4 years offshore experience)

However, employees described single health promotion offers at their workplaces, the majority of which involving gym facilities. In addition, three workers mentioned an onboard masseur. Moreover, the role of the medics on board for health promotion was highlighted. Medics were described as being responsible and approachable for health issues, and it was stated that they had given presentations about health-related topics (eg, sleep hygiene). Some employees also indicated that their companies provided them with free gym memberships for use onshore.

The workers also spoke about additional health promotion offers in previous jobs or similar settings, for example, in the seafaring and offshore oil and gas sector. They included the provision of volleyball and basketball courts, billiard, tennis, swimming pools, sauna, cinemas, nutrition initiatives and an employee assistance programme. A few workers stated that, compared with offshore wind companies, oil and gas companies invested more in their workers' health:

In the oil and gas industry, more effort is spent on 'regeneration'. [...] Companies decided to take 50000 dollars per month and invest it in onboard saunas, billiard tables, and other such things. (Worker \#5, 31-40 years, 1-2 years offshore experience)

\section{Reasons for (non-)participation in health promotion activities offshore}

The majority of the interviewees indicated that they would participate in health promotion activities offshore. A few workers stated that they would only participate in offers related to one particular field (eg, physical activity). Still others reported having a personal interest in participation but that it would require efforts to convince others who were generally not interested in health-related issues. It was, for example, mentioned that certain colleagues not only placed no value on healthy eating but were rather dismissive of it:

The known saying: 'salad shrinks the biceps' or something like that. It's all turned into ridicule first... (Worker \#19, $\geq 41$ years, $1-2$ years offshore experience)

The two workers with a programme being offered described that some of their colleagues were indeed not interested in participation, which they attributed to convenience and laziness. The difficulty of being motivated to exercise after long working days was reported as a primary reason for non-participation:

It's always difficult to overcome that lack of motivation to do anything physical after hours of working. (Worker \#6, 20-30 years, $<1$ year offshore experience)

Providing free offers scheduled in accordance with employees' work times was highlighted as important, since fee-based offers and offers taking place at unfavourable times were less attractive for the workers.

\section{Needs and wishes concerning health promotion activities offshore}

When asked about their needs and wishes regarding health promotion offers, three workers indicated being satisfied with the status quo (ie, that only gyms were provided offshore) and did not see any needs for improvement. Other workers reported only one particular wish, while still others indicated various desires. Environmental-related measures were more frequently addressed than behavioural-related measures.

Behavioural preventive measures. A general desire for more entertainment possibilities and a greater variety of activities, especially on bad weather days, was expressed:

A little more variation, especially in winter. You can have a 14day turn and 11 to 12 of those days can end up being 'weather days'. Then you just sort of sit around and 
wish there was more to do or more entertainment possibilities. (Worker \#17, 31-40 years, 1-2 years offshore experience)

The need for more social activities (eg, watching movies and cooking) was stated, explaining that such activities could reinforce the sense of community. Sports activities (to stay fit), nutritional education (to learn about healthy eating), education on relaxation techniques (to mentally detach from work) and a sauna (to relieve muscle discomfort) were also desired.

Environmental preventive measures. Employees reported the need for bigger, better-equipped and air-conditioned gyms on the platforms. They particularly stated that the size of the fitness rooms should match the crew's size:

A lot could be gained just by providing sufficient facilities [...]. Although we do have a fitness room, it's often not enough when 90 people are onboard and there are only two treadmills, two exercise bikes, and some kind of exercise bar. It just hasn't really been adapted to the workplace situation. (Worker \#2, 31-40 years, 3-4 years offshore experience)

Moreover, diverse needs in terms of physical activity were expressed. Wishes regarding free internet and telephone connections (to stay in contact with people onshore) were also described. The need for healthier food was emphasised, proposing that agreements be made between the catering crew, occupational physicians and nutrition counsellors.

\section{Quantitative approach}

Participant characteristics

The sample consisted of 303 workers who completed the relevant scales in the survey (table 2 ). The large majority of the workers $(n=287,95.7 \%)$ was male. Approximately half of the workers $(n=144,47.7 \%)$ were in their 30 s. In total, $256(84.4 \%)$ employees were in a relationship, and $275(92.0 \%)$ were German. The largest group of workers were technicians and mechanics $(n=127,42.1 \%)$, followed by workers in offshore management $(n=83,27.5 \%)$. One hundred and eighty-six $(61.1 \%)$ workers had more than 3 years of offshore experience. The proportion of companies represented by this sample was not assessable due to missing information on employees' company affiliations and on the total number of companies in the branch.

\section{RESULTS}

\section{Awareness and use of health promotion activities offshore}

Fitness facilities were by far the most often-named activity employees were aware and had made use of $(n=168$, $55.6 \%$; table 3). Only $44(14.6 \%)$ workers indicated not being aware of fitness facilities offshore. Massages were the second most-often named activity employees had used $(n=23,7.6 \%)$, followed by work-related back therapy/training $(\mathrm{n}=12,4.0 \%)$ and a physical activity/ fitness trainer $(n=10,3.3 \%)$. Otherwise, the majority of the participants was either unaware or had not used any

\begin{tabular}{|c|c|c|}
\hline & $\mathbf{n}$ & $\%$ \\
\hline Gender & 300 & \\
\hline Male & 287 & 95.7 \\
\hline Female & 13 & 4.3 \\
\hline Age (years) & 302 & \\
\hline$\leq 29$ & 57 & 18.9 \\
\hline $30-39$ & 144 & 47.7 \\
\hline $40-49$ & 64 & 21.2 \\
\hline$\geq 50$ & 37 & 12.3 \\
\hline Relationship status & 302 & \\
\hline In a relationship & 256 & 84.4 \\
\hline Single & 46 & 15.2 \\
\hline Nationality & 299 & \\
\hline German & 275 & 92.0 \\
\hline Other & 24 & 8.0 \\
\hline Occupation & 302 & \\
\hline Management onshore & 43 & 14.2 \\
\hline Management offshore/supervisor & 83 & 27.5 \\
\hline Technician/mechanic & 127 & 42.1 \\
\hline Ship's/platform crew & 15 & 5.0 \\
\hline Research staff/surveyor, medical staff & 19 & 6.2 \\
\hline Quality manager/Health and safety staff & 15 & 5.0 \\
\hline Offshore experience (years) & 302 & \\
\hline$<1$ & 22 & 7.3 \\
\hline $1-3$ & 94 & 31.1 \\
\hline$>3$ & 186 & 61.1 \\
\hline Phase of wind park & 301 & \\
\hline In construction & 101 & 33.6 \\
\hline In operation & 200 & 66.4 \\
\hline Work schedule & 303 & \\
\hline Regular schedule & 210 & 69.3 \\
\hline Occasional assignments & 93 & 30.7 \\
\hline Work shifts & 303 & \\
\hline Day shifts only & 168 & 55.4 \\
\hline Night shifts only & 1 & 0.3 \\
\hline Rotating shifts (day and night shifts) & 134 & 44.2 \\
\hline Living accommodation & 303 & \\
\hline Offshore - on a platform & 109 & 36.0 \\
\hline Offshore - on a hotel ship & 70 & 23.1 \\
\hline Offshore - on a construction ship & 48 & 15.8 \\
\hline Offshore - in a container on a platform/ship & 33 & 10.9 \\
\hline On an island/on the mainland - at a hotel or flat & 43 & 14.2 \\
\hline Cabin/room & 300 & \\
\hline Single cabin/room & 193 & 64.3 \\
\hline Shared cabin/room & 107 & 35.7 \\
\hline
\end{tabular}

Note: sample size differs between $n=299$ and $n=303$ due to missing data.

other activity. Additional offers were reported in the freetext field, for example, the consultancy with medics on health-related issues or the free use of gyms onshore. 
Table 3 Awareness and use of health promotion activities offshore

\begin{tabular}{|c|c|c|c|c|}
\hline & \multirow[b]{2}{*}{$\mathbf{n}$} & \multirow{2}{*}{$\begin{array}{l}\text { Not aware } \\
\mathrm{n}(\%)^{\star}\end{array}$} & \multirow{2}{*}{$\begin{array}{l}\text { Aware but not } \\
\text { participated } \\
\text { n (\%) }\end{array}$} & \multirow{2}{*}{$\begin{array}{l}\begin{array}{l}\text { Aware and } \\
\text { participated }\end{array} \\
\mathrm{n}(\%)^{*}\end{array}$} \\
\hline & & & & \\
\hline Fitness facilities & 302 & $44(14.6)$ & $90(29.8)$ & $168(55.6)$ \\
\hline Physical activity/fitness trainer & 302 & $278(92.1)$ & $14(4.6)$ & $10(3.3)$ \\
\hline Nutritional counselling & 303 & $280(92.4)$ & $15(5.0)$ & $8(2.6)$ \\
\hline Health counselling & 303 & $283(93.4)$ & $13(4.3)$ & $7(2.3)$ \\
\hline Ergonomics counselling & 303 & $282(93.1)$ & $17(5.6)$ & $4(1.3)$ \\
\hline Work-related back therapy/training & 303 & $275(90.8)$ & $16(5.3)$ & $12(4.0)$ \\
\hline Relaxation techniques & 303 & $284(93.7)$ & $15(5.0)$ & $4(1.3)$ \\
\hline Stress coping strategies & 302 & $285(94.4)$ & $15(5.0)$ & $2(0.7)$ \\
\hline Massage & 303 & $246(81.2)$ & $34(11.2)$ & $23(7.6)$ \\
\hline Smoking cessation programmes & 302 & $290(96.0)$ & $11(3.6)$ & $1(0.3)$ \\
\hline
\end{tabular}

Note: sample size differs between $n=302$ and $n=303$ due to missing data.

${ }^{*}$ Percentages are calculated relative to the sample sizes indicated in each column (n).

The results of the $\chi^{2}$ tests showed that employees' work schedule was statistically significantly associated with the awareness and use of fitness facilities $\left(\chi^{2}=12.024, \mathrm{df}=2\right.$, $\mathrm{p}<0.01$, Cramér's $\mathrm{V}=0.20)$ and massages $\left(\chi^{2}=7.031, \mathrm{df}=2\right.$, $\mathrm{p}<0.05$, Cramér's V=0.15; table 4$)$. Moreover, there was a statistically significant association between employees' age and the awareness and use of fitness facilities $\left(\chi^{2}=6.299\right.$, $\mathrm{df}=2, \mathrm{p}<0.05$, Cramér's $\mathrm{V}=0.15)$ and smoking cessation $\left(\chi^{2}=14.026, \mathrm{df}=2, \mathrm{p}<0.01\right.$, Cramér's $\left.\mathrm{V}=0.22\right)$. The phase of the wind park was statistically significantly associated with employees' awareness and use of massages $\left(\chi^{2}=18.827\right.$, $\mathrm{df}=2, \mathrm{p}<0.001$, Cramér's V=0.25).

The multinomial logistic regression models for fitness facilities $\left(\chi^{2}=18.213, \mathrm{df}=10, \mathrm{p}=0.05\right)$ and massages $\left(\chi^{2}=32.352, \mathrm{df}=10, \mathrm{p}<0.001\right)$ were statistically significant (table 5). Employees with a regular work schedule were more likely to be aware and have made use of fitness facilities offshore (AOR=3.22, 95\% CI 1.53 to 6.80 ). Workers in the construction phase of a wind park were more likely to be aware and have made use of massages $(\mathrm{AOR}=8.19$, $95 \%$ CI 2.82 to 23.77). Younger workers were less likely to belong to the group of those who were aware of fitness facilities but had not used them (AOR=0.43, 95\% CI 0.19 to 0.98$)$.

\section{(Non-)participation in health promotion activities offshore}

As stated by the workers who indicated being aware of at least one activity, the most frequently named reason for non-participation was a lack of interest in the existing offers ( $\mathrm{n}=43,44.3 \%$, table 6$)$. Only 17 employees $(17.5 \%)$ reported a general disinterest in health promotion offers.

Further reasons for non-participation in offers as stated in the free-text field included activities being offered at unfavourable times $(n=1)$, laziness $(n=1)$, reduced leisure time $(\mathrm{n}=1)$, and a preference for private healthcare $(\mathrm{n}=1)$.

\section{Needs and wishes for improving offshore workers' health}

In total, 121 workers answered the question of what could be done to improve their personal health offshore. The workers stated a total of 223 wishes, which were classified into behavioural and environmental preventive measures.

Behavioural preventive measures. Employees provided 61 wishes concerning behavioural measures (figure 1, online supplementary appendix B1 for detailed subcategories). Wishes were most often named with regard to physical activity ( 15 wishes), recovery (14 wishes) and health counselling (10 wishes).

Environmental preventive measures. The workers stated 162 wishes regarding environmental preventive measures (figure 2, online supplementary appendix B2 for detailed subcategories). They mostly concerned the work organisation (33 wishes), nutrition (32 wishes), accommodation (32 wishes) and physical activity (30 wishes).

\section{DISCUSSION}

Overall, findings from the qualitative and quantitative approach are in close agreement. A major result is that most employees were unaware of health promotion programmes offered at their workplaces. If one takes the workers' self-reported awareness as a surrogate measure for the existence of health promotion offers, this suggests that very few programmes are currently provided for workers in this industry. The reasons for this finding could be manifold: it could be related to the industry's young history, the workers' relatively young average age $^{9}$ and the fact that all workers must regularly demonstrate their fitness to work. ${ }^{47}$ Offshore wind workers were recently found to describe themselves as relatively healthy. ${ }^{9}$ Although they must deal with work-related health hazards, they might not yet experience critical long-term health consequences. Therefore, an urgent need for health promotion may not have been apparent 
Table 4 Results of $\chi^{2}$ tests for the associations between demographic and workplace characteristics with employees' levels of awareness and use of health promotion offers

\begin{tabular}{|c|c|c|c|c|}
\hline \multirow[b]{3}{*}{ Variables } & \multicolumn{4}{|c|}{ Level of awareness and use } \\
\hline & \multirow{2}{*}{$\begin{array}{l}\text { Not aware } \\
\mathrm{n}(\%)\end{array}$} & \multirow{2}{*}{$\begin{array}{l}\text { Aware but not } \\
\text { participated } \\
\mathrm{n}(\%)\end{array}$} & \multirow{2}{*}{$\begin{array}{l}\text { Aware and } \\
\text { participated }\end{array}$} & \multirow[b]{2}{*}{$P$ values } \\
\hline & & & & \\
\hline \multicolumn{5}{|l|}{ Fitness rooms } \\
\hline \multicolumn{5}{|l|}{ Age } \\
\hline$<40$ years $(n=201)$ & $33(16.4)$ & $51(25.4)$ & $117(58.2)$ & 0.043 \\
\hline$\geq 40$ years $(n=100)$ & $11(11.0)$ & $39(39.0)$ & $50(50.0)$ & \\
\hline \multicolumn{5}{|l|}{ Work schedule } \\
\hline Regular work schedule $(n=209)$ & $22(10.5)$ & $59(28.2)$ & $128(61.2)$ & 0.002 \\
\hline Occasional assignments $(n=93)$ & $22(23.7)$ & $31(33.3)$ & $40(43.0)$ & \\
\hline \multicolumn{5}{|l|}{ Phase of wind park } \\
\hline In construction $(n=101)$ & $13(12.9)$ & $32(31.7)$ & $56(55.4)$ & 0.830 \\
\hline In operation $(n=200)$ & $30(15.1)$ & $58(29.1)$ & $111(55.8)$ & \\
\hline \multicolumn{5}{|l|}{ Massages } \\
\hline \multicolumn{5}{|l|}{ Age } \\
\hline$<40$ years $(n=201)$ & $163(81.1)$ & $20(10.0)$ & $18(9.0)$ & 0.377 \\
\hline$\geq 40$ years $(n=100)$ & $83(82.2)$ & $13(12.9)$ & $5(5.0)$ & \\
\hline \multicolumn{5}{|l|}{ Work schedule } \\
\hline Regular work schedule $(n=210)$ & $169(80.5)$ & $20(9.5)$ & $21(10.0)$ & 0.030 \\
\hline Occasional assignments $(n=93)$ & $77(82.2)$ & $14(15.1)$ & $2(2.2)$ & \\
\hline \multicolumn{5}{|l|}{ Phase of wind park } \\
\hline In construction $(n=101)$ & $72(71.3)$ & $12(11.9)$ & $17(16.8)$ & $<0.001$ \\
\hline In operation $(n=200)$ & $173(86.5)$ & $21(10.5)$ & $6(3.0)$ & \\
\hline \multicolumn{5}{|l|}{ Smoking cessation } \\
\hline \multicolumn{5}{|l|}{ Age } \\
\hline$<40$ years $(n=200)$ & $198(99.0)$ & $2(1.0)$ & $0(0.0)$ & 0.001 \\
\hline$\geq 40$ years $(n=101)$ & $91(90.1)$ & $9(8.9)$ & $1(1.0)$ & \\
\hline \multicolumn{5}{|l|}{ Work schedule } \\
\hline Regular work schedule $(n=210)$ & $202(96.7)$ & $6(2.9)$ & $1(0.5)$ & 0.453 \\
\hline Occasional assignments $(n=93)$ & $88(94.6)$ & $5(5.4)$ & $0(0.0)$ & \\
\hline \multicolumn{5}{|l|}{ Phase of wind park } \\
\hline In construction $(n=101)$ & $96(95.0)$ & $4(4.0)$ & $1(1.0)$ & 0.364 \\
\hline In operation $(\mathrm{n}=200)$ & $192(96.5)$ & $7(3.5)$ & $0(0.0)$ & \\
\hline
\end{tabular}

${ }^{*} \mathrm{P}<0.05 ;{ }^{* *} \mathrm{p}<0.01 ;{ }^{* *} \mathrm{p}<0.001$.

Note: only those offers with statistically significant results in the $\chi^{2}$ tests are displayed.

to offshore employers. Moreover, there may be a lack of awareness among offshore companies regarding their social responsibility and the necessity of health promotion. Not providing health promotion programmes could also be a consciously made decision by the management to cut costs, which was assumed by workers in our study.

Employees emphasised that oil and gas companies seemed to invest more in workplace health promotion than companies in the wind industry. This finding is supported by reports of health promotion programmes that have been launched in the oil and gas sector ${ }^{724} 26$ and could partly be explained by the fact that the offshore oil and gas industry looks back on a longer history. With the ageing workforce of this sector, an increase in ill health and health-related costs was observed, ${ }^{78}$ so that health promotion became increasingly important. ${ }^{7}$ The German offshore wind industry might experience a similar trend in the future.

In both the qualitative and quantitative approach, fitness facilities were by far the most common offer employees were aware and had made use of. This is not surprising as gyms seem to be offered on most offshore 
Table 5 Multinomial logistic regression analysis for the associations of age, work schedule and wind park phase with employees' levels of awareness and use of health promotion offers

\begin{tabular}{|c|c|c|c|c|c|c|c|c|c|}
\hline \multirow{2}{*}{$\begin{array}{l}\text { Variable } \\
\text { Dependent }\end{array}$} & \multirow[b]{2}{*}{ Independent } & \multicolumn{4}{|c|}{$\begin{array}{l}\text { Aware but not participated versus not aware } \\
\text { (reference category) }\end{array}$} & \multicolumn{4}{|c|}{$\begin{array}{l}\text { Aware and participated versus not aware } \\
\text { (reference category) }\end{array}$} \\
\hline & & B & SE & $P$ values & AOR $(95 \% \mathrm{Cl}) \dagger$ & B & SE & $P$ values & AOR $(95 \% \mathrm{Cl}) \dagger$ \\
\hline \multirow[t]{9}{*}{ Fitness rooms } & Age & & & & & & & & \\
\hline & $<40$ years & -0.835 & 0.41 & 0.043 & $0.43(0.19$ to 0.98$)$ & -0.216 & 0.40 & 0.585 & 0.81 (0.37 to 1.80$)$ \\
\hline & $\geq 40$ years (reference) & & & & & & & & \\
\hline & Work schedule & & & & & & & & \\
\hline & Regular work schedule & 0.572 & 0.41 & 0.161 & $1.77(0.80$ to 3.94$)$ & 1.170 & 0.38 & 0.002 & 3.22 (1.53 to 6.80$)$ \\
\hline & $\begin{array}{l}\text { Occasional assignments } \\
\text { (reference) }\end{array}$ & & & & & & & & \\
\hline & Phase of wind park & & & & & & & & \\
\hline & In construction & 0.235 & 0.42 & 0.576 & 1.27 (0.55 to 2.90$)$ & 0.119 & 0.39 & 0.762 & $1.13(0.52$ to 2.44$)$ \\
\hline & In operation (reference) & & & & & & & & \\
\hline \multirow[t]{9}{*}{ Massages } & Age & & & & & & & & \\
\hline & $<40$ years & -0.167 & 0.39 & 0.670 & 0.85 (0.39 to 1.83$)$ & 0.611 & 0.56 & 0.273 & $1.84(0.62$ to 5.50$)$ \\
\hline & $\geq 40$ years (reference) & & & & & & & & \\
\hline & Work schedule & & & & & & & & \\
\hline & Regular work schedule & -0.618 & 0.41 & 0.129 & $0.54(0.24$ to 1.20$)$ & 1.427 & 0.80 & 0.074 & 4.17 (0.87 to 19.89$)$ \\
\hline & $\begin{array}{l}\text { Occasional assignments } \\
\text { (reference) }\end{array}$ & & & & & & & & \\
\hline & Phase of wind park & & & & & & & & \\
\hline & In construction & 0.288 & 0.42 & 0.492 & 1.33 (0.59 to 3.03$)$ & 2.103 & 0.54 & 0.000 & 8.19 (2.82 to 23.77$)$ \\
\hline & In operation (reference) & & & & & & & & \\
\hline
\end{tabular}

${ }^{*} \mathrm{P}<0.05 ;{ }^{* *} \mathrm{p}<0.01 ;{ }^{* * *} \mathrm{p}<0.001$.

†ORs are adjusted for employees' offshore occupation and type of shift work. Note. Reference category: not aware.

AOR, adjusted OR.

installations. ${ }^{26}$ Moreover, employees highlighted the role of the medical personnel for health promotion, although their role was not specifically inquired. This result underpins the notion that medics play a pivotal role in health management offshore. ${ }^{72628}$

We found that employees with irregular work schedules were less likely to have used fitness facilities offshore, which could likely be related to the fact that these workers spend less time offshore, making health promotion offers less available for them. Indeed, work arrangements such as temporary and irregular work have been linked to reduced feasibility and sustainability of health promotion

Table 6 Reasons for non-participation in health promotion
offers

\begin{tabular}{ll}
\hline & $\mathbf{n}(\%)^{\star}$ \\
\hline $\begin{array}{l}\text { None of the offered health promotion activities at } \\
\text { my offshore workplace were of interest to me. }\end{array}$ & $43(44.3)$ \\
I am too busy with my work. & $39(40.2)$ \\
I am too exhausted/tired after work. & $33(34.0)$ \\
I am generally not interested in health promotion & $17(17.5)$ \\
activities. & \\
\hline
\end{tabular}

*Data were only analysed for employees who had answered this question and had indicated being aware of at least one health promotion offer $(n=103)$. Percentages are calculated relative to the sample size of this subgroup. offers. ${ }^{42}$ The finding that younger workers were more likely to have used fitness facilities could be related to a generally higher interest in sports among them. Moreover, older workers were generally found to have a higher need for recovery after work. ${ }^{49}$ They may, therefore, show less willingness to engage in sports. The result is in line with evidence suggesting an age-related decrease in positive health behaviours among offshore oil and gas workers. ${ }^{7}$ With the ageing of offshore wind employees, the question of how to ensure participation of all age groups in health promotion offers may become a key issue for the future. The result that workers in the construction phase were more prone to use massages could indicate specific needs of this work group: since the construction phase was found to be linked to higher perceived physical demands, ${ }^{21}$ the workers in this phase may have a greater need for relaxing activities. However, because only few workers in our sample had used massages, CIs for this offer were wide, so that our conclusion appears less certain.

Offshore workers' reasons for non-participation in health promotion activities often concerned a lack of interest in existing activities, motivational problems and exhaustion. The lack of interest in existing offers could indicate that the current offers do not meet the workers' real needs. This seems plausible, since only few employees expressed a general disinterest in health promotion. 


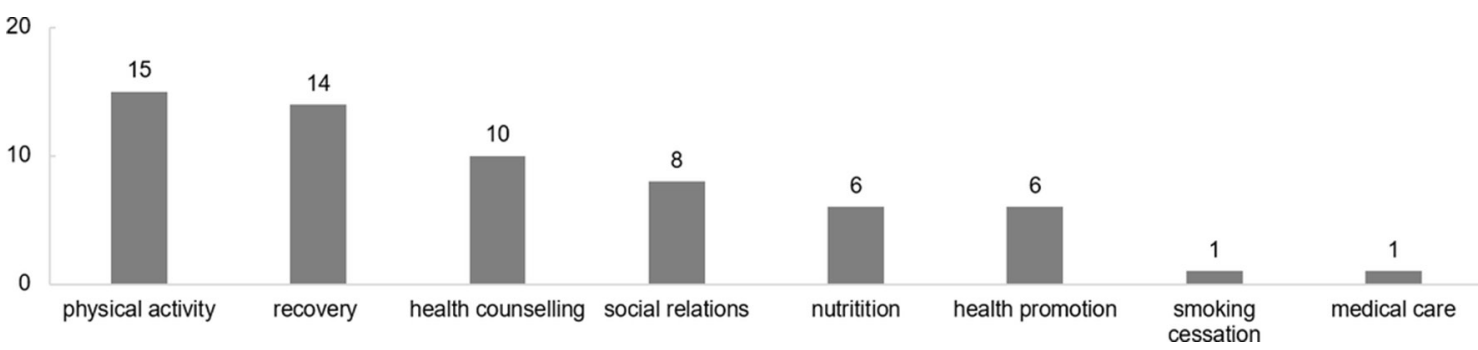

Figure 1 Categories of behavioural preventive measures. Note: absolute values of wishes are presented for each category.

The lack of motivation could either indicate a generally negative attitude towards health behaviours or suggest that workers are interested in offers but have difficulty motivating themselves after work. Offshore oil and gas workers were similarly found to report a lack of motivation and exhaustion as reasons for non-participation in health promotion. ${ }^{724}{ }^{26}$ In general, fatiguing work has been associated with lower participation rates in health promotion,$^{50}$ so that employees' intensive work hours may indeed complicate participation. However, the fact that offshore workers spend their entire time-including their leisure time-offshore could also impact positively on participation rates (eg, due to less distractions in the environment and available peer support ${ }^{5}$ ).

Emerging from both the qualitative and quantitative approach, physical activity, nutrition, social relations, recovery and health counselling were important categories for behavioural preventive measures (each being named by more than five workers in the survey). The categories correspond well with similar areas for health promotion identified in a survey among UK offshore workers. ${ }^{7}$ Moreover, they reflect the areas of activity for behavioural primary prevention prioritised by the German National Association of Statutory Health Insurance Funds. ${ }^{6}$ Notably, employees reported more desires for environmental than behavioural prevention. Similar to the preferences of oil and gas workers, ${ }^{7}$ housing improvements and the reduction of work hours were identified as relevant intervention targets. The perceived importance of environmental measures seems reasonable given the fact that employees remain permanently offshore: this implies that any environmental action taken is potentially useful to improve both their working and living environment. To reduce certain strains of the workers (eg, sleep problems), ${ }^{9}$ environmental measures could be even more effective than behavioural changes; for example, to foster their sleep quality, the reduction of noise and provision of single cabins seems more advisable than simply improving the personal sleep hygiene.

\section{Strengths and limitations}

A particular strength of our study is its mixedmethods approach, providing both qualitative and quantitative data and expanding the current scientific evidence. Moreover, we were able to incorporate the views of workers of different ages, occupations and offshore experience.

Specific strengths of the qualitative approach are the rigorous orientation on accepted field practices (eg, data analyses based on Mayring's qualitative content analysis, ${ }^{45}$ a thorough process of reflexivity, elaborate discussions on the findings and the use of direct quotes). A potential limitation is the use of telephone instead of face-to-faceinterviews, resulting in an asynchronous communication of place and reduced social cues. ${ }^{5152}$ Due to the nature of the research design, the qualitative research results are not generalisable.

Strengths of the quantitative approach consist of the use of diverse response formats (eg, multiple choice and free-text fields) in the survey and in its high accessibility, being reflected in a sufficiently large sample from a hardto-reach population. A methodological criticism is the use of self-constructed items due to a lack of validated items to assess our research questions. Moreover, the exclusive reliance on self-reported information imposes risks of bias, since the respondents' self-reported awareness may not reflect the actual amount of health promotion activities offshore. However, it seems rather unlikely that workers in the restricted offshore environment would not be aware of existing offers, especially since many

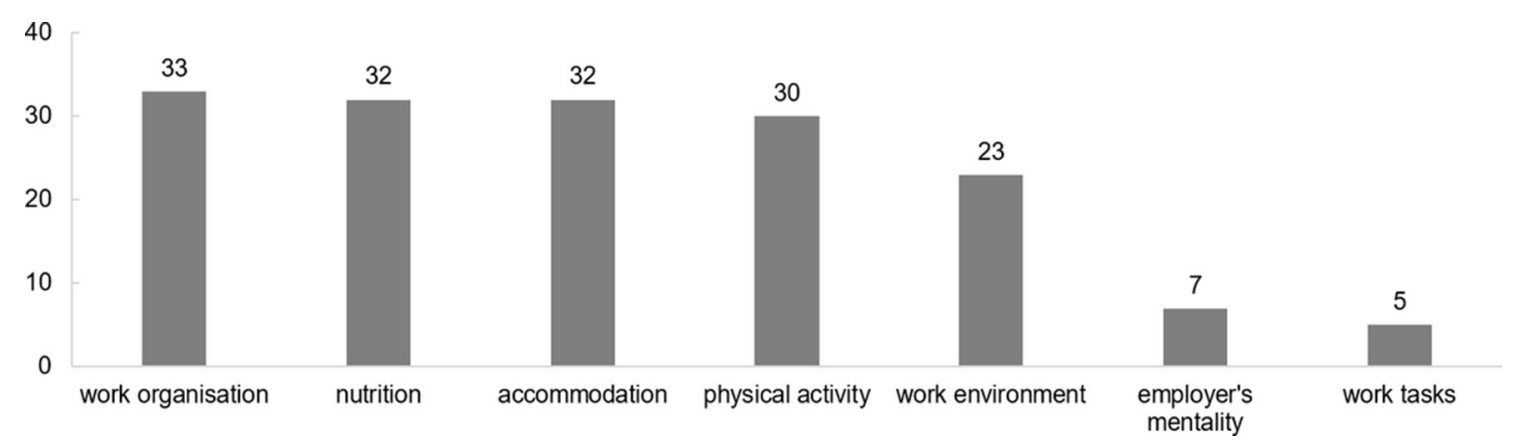

Figure 2 Categories of environmental preventive measures Note: absolute values of wishes are presented for each category. 
employees had worked offshore for several years. Even if more offers were available, lacking awareness would indicate a need for better advertising to achieve higher levels of awareness and utilisation.

Our survey sample $(n=303)$ comprises roughly $4 \%$ of our target population (workers in German offshore wind parks, $n=7600$ ). Any judgement on the extent of representativeness is difficult, as there exists no reliable data on the characteristics of the target population. At least, the representativeness of our sample was discussed thoroughly with experts from the industry (managers of offshore wind farm operators and service providers, occupational physicians, experts from German trade associations and maritime societies). They indicated that, for example, the sample's age structure seemed adequate and that the gender distribution corresponded well to the actual male-to-female ratio of the workforce. However, participation in our study was voluntary, and participants were recruited via online platforms, which implies an increased likelihood of self-selection. Motivated and health-conscious workers might have been more likely to participate in the survey, and their needs for health promotion may differ considerably from those of other workers in the branch. Moreover, a response rate cannot be calculated, so that we cannot assess the risk of a non-response bias. The existence of such biases would imply that our sample does not accurately reflect our target population and would, therefore, restrict generalisations.

\section{Implications for future research and practice}

Further studies should examine the status quo of workplace health promotion in the offshore wind industry by incorporating objective sources of information (eg, data from offshore providers) and study potential differences in offshore employers' and employees' views on the topic. Moreover, studies could examine further demographic factors that might play a role in employees' awareness and use of health promotion offers.

Concerning practical implications, our results demonstrate a perceived need for the development of health promotion offers. Based on the workers' wishes, health promotion programmes should encapsulate a broad spectrum of behavioural and environmental measures and involve basic elements of health education. Concrete offers in terms of behavioural measures may comprise the provision of a physical activity trainer, education on relaxation techniques and regularly organised social activities. Environmental measures may particularly address changes in work organisation (eg, ensuring reliable work hours and hiring more staff). They could also involve the provision of adequate training facilities, single cabins and higher quality food.

Based on our result of fatigue being a primary reason for non-participation, interventions should preferably take place during work time, which was found to increase participation. ${ }^{50}$ Employees could also be allowed to use offers during waiting times that regularly occur offshore. To counteract the lack of motivation, workers should be encouraged to define and pursue individual health-related goals and monitor their successes, for example, through the use of e-health apps or voluntary sports competitions with colleagues. Peer support was generally found to increase participation levels. ${ }^{5}$ Since social support is a strong resource for offshore wind workers, ${ }^{8}$ this is a good strategy for enhancing mutual encouragement. Our results also highlight the role of offshore medics: they could act as facilitators on the platforms and contribute to the design of health interventions with their local site knowledge. ${ }^{7}$ Therefore, it is advisable to strengthen their influence in health promotion.

Since the use of health promotion offers may partly depend on organisational and personal factors, this should be taken into account in the planning of activities. Older workers and workers with irregular work schedules should be particularly motivated to use health promotion offers (eg, by providing incentives), since these subgroups may encounter greater barriers for participation. Furthermore, health promotion offers should be tailored to the workers' needs, which may vary in different wind park phases. For example, more relaxing offers could be provided for workers in the construction phase. Fostering employees' use of health promotion activities-across all ages, work schedules and in all wind park phases-could enhance a positive 'health spirit' on the platforms.

As the workers emphasised more strongly environmental-structural than behavioural changes, this suggests that offshore employers play a key role in workplace health promotion offshore: they should recognise the long-term benefits of an investment in health and acknowledge their responsibility for the provision of offers. For this purpose, companies may draw on a wealth of experience with health promotion programmes in the oil and gas sector. Ultimately, however, it is the individual worker's responsibility to use the offers provided.

\section{CONCLUSION}

The results of our mixed-methods study suggest that only few offshore workers were aware of health promotion programmes offered at their workplace. Our findings demonstrate a perceived need for the development of health promotion programmes, since workers in our study expressed various needs and wishes for behavioural and environmental preventive measures. Given our finding that the awareness and use of health promotion offers may partly depend on organisational (eg, work schedule) and personal (eg, age) characteristics, these aspects should be taken into consideration in the planning of activities.

Acknowledgements We wish to thank all offshore companies and employees who participated in the study. Moreover, we wish to acknowledge Iris Richrath, Nora Colli and Maria Kirchhöfer for their help in data preparation as well as Jana Oestreich for her support in data analysis. We would also like to thank Rosalie McDonough for language editing.

Contributors All authors conceived of the study and participated in its design. JM conducted the interviews and performed the qualitative analyses. JM interpreted 
the qualitative data, with substantial contributions from the coauthors. JM, MVG, SM and AMP designed the online survey and recruited offshore companies and participants. JM ran the statistical analyses and drafted the manuscript. MVG, AMP, $\mathrm{VH}$ and SM gave important contributions to data interpretation and to the revision of the manuscript. All authors read and approved the final version of the manuscript.

Funding This work was supported by the German Federal Ministry of Education and Research, grant number: 01FA15029

Competing interests None declared.

Patient consent Not required.

Ethics approval The study was approved by the Medical Ethics Committee of the Hamburg Medical Association, Germany.

Provenance and peer review Not commissioned; externally peer reviewed.

Data sharing statement № additional data available.

Open access This is an open access article distributed in accordance with the Creative Commons Attribution Non Commercial (CC BY-NC 4.0) license, which permits others to distribute, remix, adapt, build upon this work non-commercially, and license their derivative works on different terms, provided the original work is properly cited, appropriate credit is given, any changes made indicated, and the use is non-commercial. See: http://creativecommons.org/licenses/by-nc/4.0/.

\section{REFERENCES}

1. Forastieri V. Psychosocial risks and work-related stress. Med Segur Trab 2013;59:297-301.

2. Ulmer J, Groeben F. Work Place Health Promotion. J Public Health 2005;13:144-52.

3. Knieps F, Pfaff H. BKK Gesundheitsreport 2016. Gesundheit und Arbeit: Zahlen, Daten, Fakten. Berlin: MWV Medizinisch Wissenschaftliche Verlagsgesellschaft, 2016.

4. World Health Organization. Healthy workplaces: a model for action: for employers, workers, policy-makers and practicioners. Geneva: World Health Organization, 2010.

5. Robroek SJ, van Lenthe FJ, van Empelen P, et al. Determinants of participation in worksite health promotion programmes: a systematic review. Int J Behav Nutr Phys Act 2009;6:26.

6. GKV-Spitzenverband. Leitfaden Prävention. 2014 https://www.gkvspitzenverband.de/krankenversicherung/praevention_selbsthilfe_ beratung/praevention_und_bgf/leitfaden_praevention/leitfaden_ praevention.jsp (accessed 15 Oct 2017).

7. Mearns K, Hope L. Health and well-being in the offshore environment: The management of personal health. Research Report 305. Sudbury: University of Aberdeen for the Health and Safety Executive, 2005.

8. Mette J, Velasco Garrido M, Harth V, et al. "It's still a great adventure" - exploring offshore employees' working conditions in a qualitative study. J Occup Med Toxicol 2017:12:35.

9. Mette J, Velasco Garrido M, Harth V, et al. Healthy offshore workforce? A qualitative study on offshore wind employees occupational strain, health, and coping. BMC Public Health 2018;18:172.

10. Parkes KR. Psychosocial aspects of work and health in the North Sea oil and gas industry. Research Report 002. Sudbury: University of Oxford for the Health and Safety Executive, 2002.

11. Berthelsen M, Pallesen S, Bjorvatn B, et al. Shift schedules, work factors, and mental health among onshore and offshore workers in the Norwegian petroleum industry. Ind Health 2015;53:280-92.

12. Ljoså CH, Tyssen R, Lau B. Mental distress among shift workers in Norwegian offshore petroleum industry--relative influence of individual and psychosocial work factors. Scand J Work Environ Health 2011;37:551-5.

13. Hennings S. Psychische Belastungen bei Offshore-Arbeiten. 2015 https://www.bghm.de/fileadmin/user_upload/Seminare/ Veranstaltungen/Werftentagung/Hennings_Psychische_Belastungen bei_Offshore-Arbeiten_20150630.pdf (accessed 28 Sep 2017).

14. Parkes KR. Offshore working time in relation to performance, health and safety: A review of current practice and evidence. Research Report RR772. Norwich: University of Oxford for the Health and Safety Executive, 2010.

15. Preisser AM, Töpel M, Harth V. Arbeitsmedizinische Eignungsuntersuchung für Mitarbeiter auf Offshoreinstallationen Von der DGMM-Empfehlung zur AWMF-Leitlinie. Flug u Reisemed 2016;23:14-18.

16. Landesamt für Gesundheit und Soziales Mecklenburg-Vorpommern. Staatlicher Arbeitsschutz im Offshorebereich. 2012 http://service. mvnet.de/_php/download.php?datei_id=68240 (accessed 26 Sep 2017).

17. Niven K, McLeod R. Offshore industry: management of health hazards in the upstream petroleum industry. Occup Med 2009;59:304-9.

18. Gardner R. Overview and characteristics of some occupational exposures and health risks on offshore oil and gas installations. Ann Occup Hyg 2003;47:201-10.

19. Parkes KR. Shift schedules on North Sea oil/gas installations: A systematic review of their impact on performance, safety and health. Saf Sci 2012;50:1636-51.

20. Parkes KR. Shiftwork, job type, and the work environment as joint predictors of health-related outcomes. J Occup Health Psychol 1999;4:256-68.

21. Velasco Garrido M, Mette J, Mache S, et al. A cross-sectional survey of physical strains among offshore wind farm workers in the German exclusive economic zone. BMJ Open 2018;8:e020157.

22. O'Sullivan M, Edler D, Lehr U. Ökonomische Indikatoren des Energiesystems. Methode, Abgrenzung und Ergebnisse für den Zeitraum 2000-2016. GWS Research Report 2018/01. Osnabrück: GWS mbH Osnabrück, 2018.

23. Colli N, Mache S, Harth V, et al. Physische und psychische Gesundheit von Offshore-Beschäftigten. Zbl Arbeitsmed 2017;67:176-8.

24. Mearns K, Diet FC. Health and the Offshore Worker: A Pilot Study. Offshore Technology Report. Sudbury: Robert Gordon University for the Health and Safety Executive, 1994.

25. Corpes $\mathrm{A}$. Offshore installations benefit from nutrition training programmes. Perspect Public Health 2013;133:286.

26. Mearns K, Hope L, Reader TW. Health and well-being in the offshore environment: The role of the organisational support. Research Report 376. Sudbury: University of Aberdeen for the Health and Safety Executive, 2006.

27. Thorne HC, Hampton SM, Morgan LM, et al. Returning from night shift to day life: Beneficial effects of light on sleep. Sleep Biol Rhythms 2010;8:212-21.

28. Colli N, Mache S, Harth V, et al. Gesundheitsförderung von OffshoreBeschäftigten. Zbl Arbeitsmed 2017;67:345-8.

29. Mearns K, Hope L, Ford MT, et al. Investment in workforce health: exploring the implications for workforce safety climate and commitment. Accid Anal Prev 2010;42:1445-54.

30. Puskeppeleit M. Medizin im Offshore-Bereich. In: Ottoman C, Seidenstücker KH, eds. Maritime Medizin: Praxiswissen für Schiffsärzte und Ärzte im Offshore-Bereich. Berlin, Heidelberg: Springer, 2015.

31. Burton J. WHO healthy workplace framework and model: background and supporting literature and practices. Geneva: World Health Organization, 2010.

32. Franzkowiak P. Prävention und Krankheitsprävention. Leitbegriffe der Prävention und Gesundheitsförderung. Köln: Bundeszentale für gesundheitliche Aufklärung (BZgA), 2011:437-47.

33. Maes L, Van Cauwenberghe E, Van Lippevelde W, et al. Effectiveness of workplace interventions in Europe promoting healthy eating: a systematic review. Eur J Public Health 2012;22:677-83.

34. Ni Mhurchu C, Aston LM, Jebb SA. Effects of worksite health promotion interventions on employee diets: a systematic review. BMC Public Health 2010;10:62.

35. Conn VS, Hafdahl AR, Cooper PS, et al. Meta-analysis of workplace physical activity interventions. Am J Prev Med 2009;37:330-9.

36. Proper KI, Koning M, van der Beek AJ, et al. The effectiveness of worksite physical activity programs on physical activity, physical fitness, and health. Clin J Sport Med 2003;13:106-17.

37. Anderson LM, Quinn TA, Glanz K, et al. The effectiveness of worksite nutrition and physical activity interventions for controlling employee overweight and obesity: a systematic review. Am J Prev Med 2009;37:340-57.

38. Kuoppala J, Lamminpää A, Husman $P$, et al. Work health promotion, job well-being, and sickness absences--a systematic review and meta-analysis. J Occup Environ Med 2008;50:1216-27.

39. Odeen M, Magnussen LH, Maeland S, et al. Systematic review of active workplace interventions to reduce sickness absence. Occup Med 2013;63:7-16.

40. Chapman LS. Meta-evaluation of worksite health promotion economic return studies: 2012 update. Am J Health Promot 2012;26:1-12.

41. Bräunig D, Haupt J, Kohstall T, et al. iga. Report 28: Wirksamkeit und Nutzen betrieblicher Prävention. Berlin: Initiative Gesundheit und Arbeit (iga), 2015.

42. Peltomäki P, Johansson M, Ahrens $W$, et al. Social context for workplace health promotion: feasibility considerations in Costa 
Rica, Finland, Germany, Spain and Sweden. Health Promot Int 2003;18:115-26.

43. Teddlie C, Yu F. Mixed methods sampling: a typology with examples. $J$ Mix Methods Res 2007;1:77-100.

44. VERBI Software Consult Sozialforschung GmbH. MAXQDA 12: Reference Manual. 2014 http://www.maxqda.com/download/ manuals/MAX12_manual_eng.pdf (accessed 5 Oct 2017).

45. Mayring P. Qualitative Inhaltsanalyse [Qualitative Content Analysis]. Forum Qual Soc Res 2000;1.

46. IBM SPSS. Statistics 24 Brief Guide. ftp://public.dhe.ibm.com/ software/analytics/spss/documentation/statistics/24.0/en/client/ Manuals/IBM_SPSS_Statistics_Brief_Guide.pdf (accessed 14 Oct 2017).

47. Preisser AM, Decker U, Faesecke KP, et al. S1-Leitlinie 002/43: Arbeitsmedizinische Eignungsuntersuchung für Arbeitnehmer auf Offshore-Windenergieanlagen und anderen Offshore-Installationen. 2015 http://www.awmf.org/uploads/tx_szleitlinien/002-043I_S1_
Arbeitsmedizinische_Eignungsuntersuchung_Offshore_2015-02.pdf (accessed 20 Oct 2017).

48. Bjerkeboek E, Wiig H, Heber H. Ageing of the offshore workforce in the Norwegian offshore industry: implications for safety and health. Proceedings at the occupational health offshore conference: offshore technology report 2001/041. Oxfordshire: AEA Technology Environment for the Health and Safety Executive, 2002.

49. Kiss P, De Meester M, Braeckman L. Differences between younger and older workers in the need for recovery after work. Int Arch Occup Environ Health 2008;81:311-20.

50. Jørgensen MB, Villadsen E, Burr H, et al. Does employee participation in workplace health promotion depend on the working environment? A cross-sectional study of Danish workers. BMJ Open 2016;6:e010516.

51. Opdenakker RJG. Advantages and disadvantages of four interview techniques in qualitative research. Forum Qual Soc Res 2006;7.

52. Novick $G$. Is there a bias against telephone interviews in qualitative research? Res Nurs Health 2008;31:391-8. 